Canadian Journal of Fisheries and Aquatic

Sciences

June 2008, Volume 65 (6): Pages 1024-1035

http://dx.doi.org/10.1139/F08-028

(c) 2008 National Research Council Canada
Archimer http://www.ifremer.fr/docelec/ Archive Institutionnelle de l'Ifremer

The original publication is available at http://pubs.nrc-cnrc.gc.ca

\title{
A two-stage biomass random effects model for stock assessment without catches: What can be estimated using only biomass survey indices?
}

\author{
Verena M. Trenkel ${ }^{1, *}$ \\ ${ }^{1}$ Ifremer, Department Ecology and Models for Fisheries, BP 21102, 44311 Nantes, France \\ *: Corresponding author : V. Trenkel, . tel: +33 2 40374108, fax: +33 2 40374075, email address : \\ verena.trenkel@ifremer.fr
}

\begin{abstract}
A simple two-stage biomass random effects population dynamics model is presented for carrying out fish stock assessments based on survey indices using no commercial catch information. Recruitment and biomass growth are modelled as random effects, reducing the number of model parameters while maintaining model flexibility. No assumptions regarding natural mortality rates are required. The performance of the method was evaluated using simulated data with emphasis on identifying parameter redundancy, which showed that the variance of the biomass growth random effect might only be estimable if large (>0.2). The full and two nested models were fitted to European anchovy (Engraulis encrasicolus) in the Bay of Biscay using two survey series. The best-fitting model had fixed biomass growth and random recruitment following a lognormal distribution.
\end{abstract}

Résumé : Afin d'évaluer des stocks sur la base d'indices de campagnes sans données de captures commerciales, nous proposons un modèle de dynamique de population en biomasse à deux stades avec effets aléatoires. Le recrutement et la croissance de la biomasse sont modélisés comme des effets aléatoires, ce qui réduit le nombre de paramètres à estimer en gardant la flexibilité du modèle. Aucune hypothèse de mortalité naturelle n'est requise. La performance du modèle, en particulier, l'identification des paramètres redondants, a été évaluée par simulation, ce qui a montré que la variance de la croissance de la biomasse n'est estimable que si elle est grande $(>0,2)$. Le modèle complet ainsi que deux modèles emboîtés ont été ajustés à deux séries d'indices de campagnes pour l'anchois commun (Engraulis encrasicolus) dans le golfe de Gascogne. Dans le modèle qui s'ajustait le mieux, la croissance de la biomasse était constante et le recrutement avait une distribution lognormale.

Keywords: random effects, population state, survey-based assessment. 


\section{Introduction}

Unavailability or unreliability of commercial catch information have spurred the development of fish stock assessment methods that only use survey indices and do not require catch data. For example Cook (1997) proposed an age-structured stock assessment model which uses only survey indices for estimation; the model was applied to haddock by Beare et al. (2005). In addition to unreliable catch data, no age sampling data might be available for a given stock, either because ageing is difficult or too costly. However, it might still be possible to obtain survey indices for recruits and either the recruited proportion of the stock or the total stock including recruits. Possibly these indices will be in biomass not in numbers. Clearly in this data limited case, a simple and parsimonous stock assessment model is required.

A range of simple stock assessment models have proposed in the literature. The best known surplus production biomass model is the Schaefer model and its derivations (Hilborn and Walters, 1992). One step up from this are two-stage models that account separately for adults and recruits (Collie and Sissenwine, 1983; Hoenig and Gedamke, 2007; Mesnil, 2003). Most existing simple models, in biomass or numbers, have in common that catches are subtracted, hence need to be known. The exception is the model proposed by Hoenig and Gedamke (2007) in which instead of subtracting catches, survival rates of recruits and recruited animals are modelled. However, constant survival rates over time have to be assumed for model parameters to be identifiable.

Here a two-stage discrete biomass model is proposed that, similar to the model by Hoenig and Gedamke (2007), has a term for survival or rather biomass growth. However, the proposed model differs in two important aspects. First, biomass growth is not fixed between years, and secondly recruitment, although also variable between years, is assumed to come from a statistical distribution, for example a lognormal distribution, which reduces the number of parameters to two instead of being equal to the number of years. Practically this is achieved by modelling recruitment and biomass growth as random effects. For recruitment this choice is motivated by the results of the simulation study carried out by Maunder and Deriso (2003). These authors compared the performance of four different methods for estimating recruitment in catch-at-age models, including maximum likelihood estimation of annual recruitment, a random effects method (termed importance sampling of the marginal likelihood) and Bayesian estimation. They found that the random effects method and the Bayesian method performed best in terms of estimating annual recruitment and the standard deviation of the recruitment residuals. It seemed natural to use the same approach for estimating biomass growth. Alternatively a Bayesian approach could have been used as demonstrated by Porch et al. (2006) for an age-structured model using only survey data and no catches.

The focus of this study is on model parameter identifiability, that is how many and which model parameters can be estimated for a given model with a given data set. A model is defined to be identifiable if no two values of the parameters give rise to the same distribution function resulting in different parameter values being associated with the maximum likelihood of any set of observed data (Gimenez et al., 2004). A model that is non-identifiable has redundant parameters. For any given model, there are two levels of redundancy. Intrinsic redundancy is a model property while for any actual data set there can be extrinsic redundancy, i.e. all model parameters are not identifable using the particular data set. There are several methods for detecting the number of redundant parameters (Gimenez et al., 2004). The number of positive eigenvalues of the Hessian matrix at the maximum likelihood informs on model rank, which corresponds to the number of estimable parameters. Nonzero values in the eigenvector corresponding to zero eigenvalues identify which parameters are redundant. This method can be applied to detect intrinsic and extrinsic parameter redundancy using simulated and real data respectively. Intrinsic parameter redundancy can also be evaluated in simulation studies where estimates and true values are compared.

In the next section the details of the proposed model are provided. Model properties, in particular parameter redundancy are then studied in three simulation studies. Finally the full model and two nested sub-models are applied and compared for anchovy in the Bay of Biscay.

\section{Two-stage biomass random effects model}

The population dynamics are modelled as

$$
B_{t}=R_{t}+g_{t-1} B_{t-1}
$$


where $B_{t}$ is the total population biomass, $R_{t}$ the recruitment in biomass in year $t$ and $g_{t-1}$ the biomass growth rate during year $\mathrm{t}-1$ which is the result of individual growth and survival (including natural and fishing mortality). Recruitment is assumed to follow a lognormal distribution with no autocorrelation or any relationship between the spawning stock and recruits

$$
\log \left(R_{t}\right) \sim N\left(\mu_{R}, \sigma_{R}^{2}\right)
$$

Biomass growth is modelled by a random walk on the log-scale

$$
\log \left(\mathrm{g}_{\mathrm{t}}\right)=\log \left(\mathrm{g}_{\mathrm{t}-1}\right)+\varepsilon_{\mathrm{t}} \text { with } \varepsilon_{\mathrm{t}} \sim \mathrm{N}\left(-0.5 \sigma_{\mathrm{g}}{ }^{2}, \sigma_{\mathrm{g}}{ }^{2}\right) .
$$

This formulation implies that the effects of catches on the inter-annual variation of the integrative parameter $g_{t}$ are either random or, if not, sufficiently small not to matter. Thus both recruitment $R_{t}$ and biomass growth $\mathrm{g}_{\mathrm{t}}$ are treated as random effects.

The observation model has two components. The first one is for observations of total biomass $b_{t}$ at time $t$ (recruits included) and the second for observations of recruits $r_{t}$. This formulation has been developed for the case where one survey method is used to obtain a total biomass index and a different method for the recruit index although the recruit index might rely partly on the same information. Both indices are assumed to follow lognormal distributions with the variance for the recruit index being a multiple of that for the total biomass index and each have separate constants of proportionality

$$
\begin{aligned}
& \log \left(b_{t}\right) \sim N\left(\log \left(q_{b} B_{t}\right), \sigma_{1}^{2}\right) \\
& \log \left(r_{t}\right) \sim N\left(\log \left(q_{r} R_{t}\right), \alpha \sigma_{l}^{2}\right) .
\end{aligned}
$$

To make the model identifiable, $q_{b}$ is set to 1 but $q_{r}$ is estimated. Hence all population biomass estimates are relative to the index for which $q$ is fixed to 1 . Furthermore, $\alpha=1$, but any other value could be chosen for a given case study. If two survey series are used for the same time period, separate constants of proportionality are fitted for each survey series, but again constraining the constant of proportionality of one of the survey series to one. Thus, in that case the observation model parameters are $q_{b}^{1}$ and $q_{r}^{1}$ for total biomass and recruitment biomass of survey $1, q_{b}^{2}$ and $q_{r}^{2}$ for the corresponding constants of proportionality of survey 2. Again, some constraints are necessary: either $q_{b}^{1}=1$ or $q_{b}^{2}=1$. For any lognormally distributed variable $x, V[\log (x)] \approx \log \left(c v(x)^{2}+1\right)$, given $\operatorname{cv}(x)$ is small. Hence instead of estimating survey observation errors $\sigma_{I}^{1}$ and $\sigma_{I}^{2}$, the coefficient of variations $C V_{1}^{1}$ for survey 1 and $C V_{1}^{2}$ for survey 2 are estimated.

\subsection{Parameter estimation}

Estimation of model parameters $\boldsymbol{\theta}$ (see Table 1 ) is carried out by maximum likelihood based on the observation vector $\boldsymbol{y}=\left(b_{1}, \ldots, b_{n}, r_{2}, \ldots, r_{n}\right)$ which has conditional density $f_{\theta}(\mathbf{y} \mid \mathbf{u})$ where $\boldsymbol{u}=\left(R_{2}, \ldots, R_{n}\right.$, $\left.g_{2}, \ldots, g_{n}\right)$ is the vector of latent random variables with marginal density $h(u)$. The marginal likelihood function is obtained by integrating out $\mathbf{u}$ from the joint density $f_{\theta}(\mathbf{y} \mid \mathbf{u}) h_{\theta}(\mathbf{u})$

$$
L(\boldsymbol{\theta})=\int f_{\theta}(\mathbf{y} \mid \mathbf{u}) h_{\theta}(\mathbf{u}) d \mathbf{u}
$$

The joint penalized loglikelihood is $P L(\theta)=\log \left(f_{\theta}(y \mid \mathbf{u})\right)+\log \left(h_{\theta}(\mathbf{u})\right)$.

The integral in (6) is evaluated using the Laplace approximation as implemented in the random effects module of AD Model builder and described in Skaug and Fournier (2006). AD Model builder automatically calculates standard deviations of estimates based on the observed Fisher Information matrix. 


\section{Simulation studies}

\subsection{Simulation study 1: Parameter redundancy}

To investigate the parameter redundancy in the proposed biomass model (eqs. 1-5) given the constant of proportionality for total biomass $q_{b}=1$ and the ratio between survey variances $\alpha=1$, observations were simulated using the same model as for the estimation. The usefulness of the recruit survey index in addition to the total biomass index for the estimation was evaluated by comparing parameter estimates with and without the use of a recruit index. Two scenarios were investigated in each case, one with a small value for the interannual variability in biomass growth $\left(\sigma_{g}{ }^{2}=0.02\right)$ and one with a much larger value $\left(\sigma_{\mathrm{g}}{ }^{2}=0.2\right)$ to increase the variance in the data for biomass growth estimation. Finally, the observation equations 4) and 5) assume that recruit and total biomass survey indices have independent errors. To evaluate the impact violation of this assumption might have on parameter estimates, a scenario with correlated observation errors for the total and recruit biomass index in each year $t$ was simulated $\left(\varepsilon_{\mathrm{b}, \mathrm{t}}=\varepsilon_{\mathrm{r}, \mathrm{i}}, \varepsilon_{\mathrm{r}, \mathrm{t}} \sim \mathrm{N}\left(0, \sigma_{\mathrm{l}}^{2}\right)\right)$.

For each scenario, 20 years of 100 population trajectories and one realisation of survey observations for each trajectory were simulated. Parameter estimation started from the true values in all cases. Table 1, last column, gives the parameter values used for the simulations.

Comparing estimated parameter values with true values for the scenario with small $\sigma_{g}$, it appeared that histograms of estimated parameters were centred on the true values for all parameters except $\sigma_{\mathrm{g}}$ which was estimated as zero, or rather a very small values corresponding to the lower bound in the estimation procedure (Fig. 1a). The estimates of this parameter became non-zero for $70 \%$ of population realisations when the true parameter value was large (Fig. 1b). Thus the actual value of the interannual variability in biomass growth influences the estimability of this parameter, i.e. the fact that parameter estimates are less often running up against the boundary which implies that the parameter is less often redundant. Parameter redundancy will be investigated more formally below. When estimation model parameters using only a total biomass index and no recruit index, estimates of survey $\mathrm{CV}_{1}$ tended to be zero for a large majority of trajectories and $\sigma_{\mathrm{g}}$ was also generally not estimable (Figs. 1c\&d). Thus the use of the recruit index series allowed more accurate and precise estimation of survey index CVs and of the recruitment distribution. In the case of using survey indices with correlated observation errors, only the estimates of survey uncertainty $\mathrm{CV}_{1}$ itself were mainly affected by being underestimated and none of the other parameters apart from $\sigma_{g}$ (Fig. 1e). Hence, if survey indices are correlated instead of independent as assumed by the model, the magnitude of the survey uncertainty will be underestimated.

To investigate the confounding of model parameter estimates, Table 2 provides as an example correlation estimates from the scenario with large interannual variability in biomass growth (corresponding to Fig 1b). The lower triangular part of the matrix shows the minimum, median and maximum pair-wise correlations across the 100 simulations. Several parameter estimates were found to be strongly correlated indicating they may be confounded. The constant of proportionality $\mathrm{q}_{\mathrm{r}}$ of the recruit index was strongly positively correlated with biomass growth $g_{1}$, and strongly negatively correlated with biomass growth uncertainty $\sigma_{g}$ and average recruitment $\mu_{R}$. Estimates of $\mu_{R}$ were further negatively correlated with $g_{1}$ and positively with $\sigma_{g}$, which in turn was negatively correlated with $\mathrm{CV}_{1}$.

For each simulation of all five scenarios, model rank was determined from analysis of the non-zero $\left(<10^{-6}\right)$ eigenvalues of the Hessian matrix at the maximum likelihood estimates. Full rank (seven parameters) was found for $10 \%$ and $70 \%$ of simulations for the scenarios with small (Fig. 1a) and large $\sigma_{g}$ (Fig. 1b) values respectively that used both survey indices. The remaining simulations had rank six with the parameter $\sigma_{g}$ being redundant. For the scenarios with no recruit survey index, model rank was only five for all simulations with small (Fig. 1c) and $60 \%$ of simulations with large $\sigma_{g}$ (Fig $1 d$ ) and rank six for the remainder. The parameters that were redundant varied between simulations and affected all parameters except $\mu_{R}$ and $q_{r}$ which were always estimable. In the case of survey series with correlated observation errors $\left(\sigma_{g}=0.2\right.$; Fig. 1e) $66 \%$ of simulations had full model rank, while model rank was only six for $34 \%$ of simulations in which case either $\sigma_{g}$ or $C V_{1}$ were redundant. So in general $\sigma_{g}$ tended to be redundant while all other parameters proved to be estimable to various degrees in the different scenarios. 


\subsection{Simulation study 2: Impact of fishing history and survey index uncertainty}

This simulation study addresses the issue of the impact of fishing history, underlying natural mortality rates and survey index precision on model parameter estimates. Fish population trajectories were simulated using an age-structured population dynamics model with size-selective fishing, stochastic recruitment following a Beverton-Holt function and variations in fishing mortality over time (for a description of the model see appendix of Mesnil 2003). Three scenarios were simulated intended to represent common fishing histories and species characteristics. The first two scenarios imitate longer lived species with relative low natural mortality $(\mathrm{M}=0.2)$ and randomly varying fishing mortality (range 0.4-0.7) for scenario F1 and increasing fishing mortality towards the end of the series for scenario F2 (increase from 0.4 to 0.75 ). The third scenario $\mathrm{M} 1$ is the same as the first but for shorter lived species such as anchovy with higher natural mortality $(M=0.8)$. For each scenario, one population trajectory was simulated from which 100 survey indices were drawn for a range of observation errors. The scaled trajectories of total population biomass are shown in Fig. 2. Simulated survey indices in numbers were transformed into indices in biomass by multiplying numbers-at-age by constant weightat-age values and then summing over all 15 ages for the total biomass index.

For scenario F1, coefficients of variations of parameter estimates increased with the uncertainty in survey indices (Fig. 3a). The increase was strongest for the survey constant of proportionality $\mathrm{q}_{\mathrm{r}}$ and least for the estimate of survey uncertainty $\mathrm{CV}_{1}$. The overall most precisely estimated parameter was mean recruitment $\mu_{R}$ and recruitment variability $\sigma_{R}$ was the least precisely estimated. It might appear surprising at first, that $\sigma_{\mathrm{g}}$ was estimated in more simulation runs when survey uncertainty was large, about $40 \%$ of simulations for a $\mathrm{CV}_{1}$ of 0.5 and only $20 \%$ for a $\mathrm{CV}_{1}$ of 0.3 . However, more uncertainty in survey indices can also be interpreted as larger interannual variability in biomass growth, which as simulation study 1 showed makes this parameter less likely to be redundant. When comparing true to estimated survey uncertainties, a clear negative bias appeared where the bias increased with increasing values of $\mathrm{CV}_{\mathrm{i}}$ (Fig. 3b). The root mean squared error (RMSE), defined as the square root of the mean over years and simulations of the squared deviations between estimates and truth, of total population biomass estimates did not depend on survey index $\mathrm{CV}_{1}$ (Fig. 3c). In contrast, RMSE for recruit biomass estimates increased linearly with survey index $\mathrm{CV}_{1}$ (Fig. 3d).

From the comparison of coefficients of variations across simulation scenarios $\left(\mathrm{CV}_{1}=0.3\right)$ it appeared that the type of fishing history and natural mortality level had a great impact on the coefficient of variation of model parameter estimates (Fig. 4). Most affected was the CV of recruitment variability $\sigma_{R}$, followed by mean recruitment $\mu_{R}$ and recruit survey $q_{R}$. Survey $C V_{1}$ was underestimated in all scenarios (true value 0.3). In the detailed study of scenario F1 above, it was also found that the bias increased as the simulated survey $\mathrm{CV}_{1}$ increased. Scenario $\mathrm{F} 2$ with higher fishing mortalities at the end of the time series was the least informative leading to the most imprecise parameter estimates, i.e. highest CVs in Fig. 4. Second was scenario M2 with higher natural mortality compared to scenario F1 which provided the most information for model parameter estimation. As the population dynamics model used for simulation was different from the fitted model, model misspecification was present in all cases.

\subsection{Simulation study 3: National Research Council scenarios}

The five data sets simulated for the US National Research Council rounds of tests of various fish stock assessment methods during 1997 were used to further explore the performance of the proposed model. Four data sets correspond to a fishing history of depletion and one to a recovery situation; a sixth set was added for a two-way trip and no observation error (Table 3 ). The advantage using a standard data set is that the outcome has been published (NRC, 1998), enabling the performance of any proposed method to be compared with that of the methods considered then. The data were generated by an age-structured population model, where a 15-age population was projected over some 40 years but data for only the last 30 years were retained. Details of the data generation are given in Chapter 5 and Appendix E of the NRC report. Fishing mortality was adjusted in the simulations as to obtain the desired trend in population abundance. Each data set is a single replication of a combination of stochastic processes. A special comment applies to data set 3 , which involves a change in survey vessel (and a near doubling of the survey catchability q), a feature that is a clear violation of basic model assumptions. Data set 5 simulates a case with very low exploitation rate.

Two performance measures were calculated. For each quantity of interest, the time series of estimates, on the one hand, and of true values, on the other hand, were first normalised by subtracting the respective mean and dividing by their standard deviation, which gives a common scaling. Then the 
RMSE was computed. The estimated biomass depletion, that is $\hat{B}_{30} / \hat{B}_{1}$ as considered in the NRC tests was also retained as an indicator for comparisons, together with the NRC criterion that the relative estimation error, $100 *\left(\hat{B}_{30} / \hat{B}_{1}-B_{30} / B_{1}\right) /\left(B_{30} / B_{1}\right)$, where $\left(B_{30} / B_{1}\right)$ is the true depletion, should be smaller than $\pm 25 \%$.

The comparison between true biomass and estimated biomass showed that estimates followed the time trends but were smoother for some simulation sets (Figure 5). The exception was set 3 for which a change in catchability in the middle of the time series was ignored in the estimation model. This led to an error in the estimated time trend around that point which resulted in a large root mean square error (RMSE) for both total biomass and recruit estimates (Table 3, column 5 and 6). In contrast, biomass trends for set 6 with no observation error were most precisely estimated, i.e. scaled total and recruit biomass estimates had the smallest RMSE. The results for all other sets were similar. Thus the type of simulated fishing history (depletion or recovery) did not have any impact on the error of estimated biomass trends. However, ignored changes in survey catchability (simulation set 3 ) had a large impact. Depletion estimates were within the $25 \%$ limit for four out of the six data sets. None of the six models tested by the NRC provided satisfactory depletion estimates for simulation set 3 , while depletion estimates were within the limit for one to three out of five tested models depending on the simulation set (Table 3, last column).

\section{Case study: Anchovy in Bay of Biscay}

\subsection{Survey indices}

Biomass survey indices for anchovy (Engraulis encrasicolus) from Spanish and French surveys taking both place in the Bay of Biscay in May every year were available for the period 1989 to 2005, with some missing years (ICES, 2006). Spain carries out an egg survey and uses the daily egg production method (DEPM), estimates of daily fecundity and regional population age structure to estimate total biomass and biomass at age 1 (Somarakis et al., 2004). The French biomass indices are based on acoustic data and pelagic trawl hauls for species identification (Massé, 1996). Age 1 indices are obtained using length-frequency distributions per sampling unit and a global age-length key. For this survey, age 1 biomass was estimated from numbers by assuming a mean weight of 15 gram per individual. All survey indices were divided by 1000 for model fitting. Given the recruit indices were obtained from data collected during the same survey as for the total biomass index, although in both cases splitting into age classes was done on a regional basis, both indices are expected to be correlated to some degree. The results of simulation study 1 have shown that in the case of correlation between the two indices, estimates of survey uncertainty $C V_{1}$ are likely to be underestimated but none of the other model parameters should be much affected.

\subsection{Models}

The simulations studies reported above showed that certain parameters of the proposed two-stage random effects biomass model might not be estimable independently ( $\mu_{R}, g_{1}$ and $q_{r}$ are confounded), while $\sigma_{g}$ might not be estimable at all. Survey uncertainty $\left(C_{1}\right)$ was found to be often underestimated, in particular when the observation error of the two survey series was correlated. Therefore three nested models were fitted to the anchovy data and compared by likelihood ratio tests. The p-values from these tests are only approximate and should be treated with care in case of borderline results (see discussion in Wood 2006, section 6.2.3). The base-line model, called RE-g, corresponds to the full model (eqs. 1-5) with a random effet for biomass growth. In the constant growth model, FE-g, biomass growth is treated as a fixed effect across years $\left(\sigma_{g}=0\right)$. Finally, in the constant growth and known survey uncertainty model, FE-g-CV, $\mathrm{CV}_{1}$ is fixed at some suitable value in addition to constant biomass growth. For the DEPM indices, a CV of 0.2 taken from ICES (2006) was used. For the acoustic indices, a CV of 0.16 as estimated by Petitgas et al. (2003) was employed. For all three models, the constant of proportionality of the acoustic total biomass index was set to one $\left(q_{b}^{\text {acoustic }}=1\right)$. This is an arbitrary choice, to explore its consequences, the value was varied between 0.1 and 1.2. In addition, the constant of proportionality of the DEPM index, $q_{b}^{D E P M}$, was also fixed at different values. To check that the assumption of an independent random distribution was reasonable for recruitment, the autocorrelation function was calculated for each recruitment survey index. There was clearly no 
sign for any autocorrelation (results not shown). As for the type of distribution, assuming a log-normal distribution for recruitment seemed reasonable; Bergh and Butterworth (1987) made the same assumption when studying management options for South African anchovy.

\subsection{Anchovy results}

The three nested models were compared using approximate likelihood ratio tests (Table 4, column 4). The best model was model FE-g with constant biomass growth across years. Analysis of the Hessian matrix showed that all parameters were estimable in models FE-g and FE-g-CV, while there was one redundant parameter in model RE-g which turned out to be the interannual variability in biomass growth $\sigma_{\mathrm{g}}$.

Model parameter estimates did not differ much between models (Table 4 right hand columns). CVs of parameter estimates were generally in the range 0.2-0.3 for models RE-g and FE-g; CVs of parameter estimates were about halved when survey CVs were fixed (model FE-g-CV). A noticeable exception were the parameter estimates for $\sigma_{R}$. The CV of the estimate of this parameter was high for all models. The standard error of biomass growth $\sigma_{g}$ was not actually estimable in model RE-g (estimate corresponded to lower parameter bound). Estimates of the constant of proportionality for recruits were smaller than those for total biomass indices for the acoustic time series, but about the same or larger for the DEPM series. Point estimates for survey CVs were 0.49 for the acoustic indices and 0.31 for the DEPM indices. This is much larger than the values assumed in model FE-g-CV, which were 0.16 and 0.2 respectively.

Some parameter estimates were strongly correlated (Table 5). The constants of proportionality for the two recruit indices were positively correlated with each other and also with the annual year biomass growth $g$ and negatively correlated with the mean recruitment level $\mu_{R}$. All other parameter estimates were less correlated.

Population biomass estimates (95\% confidence bands based on assuming normal distributions) for the three models are given in Fig. 5. Note that estimates from models RE-g and FE-g have identical confidence bounds. The most noticeable feature of these figures is that by fixing survey uncertainty instead of estimating it, the confidence intervals for total and recruit biomass estimates with model FE$\mathrm{g}-\mathrm{CV}$ were much tighter than for the other two models.

To check model assumptions, residual qq-plots were investigated for the best model FE-g (Figure 6). Residuals from total biomass indices followed the expected standard normal distribution quite well, whereas there were some problems for residuals from the recruitment indices. The lognormal distribution assumptions was not completely satisfactory for the recruitment indices, as the quantiles departed from the diagonal at small and large quantiles. Thus a different distribution might be more appropriate. However, trials with recruitment being modelled by a normal approximation to a Poisson distribution or a Normal distribution did not lead to better results.

Finally, to investigate the impact of the arbitrary choice of setting the constant of proportionality for the acoustic total biomass index to one, the penalised loglikelihood function was compared for a range of values for $q_{b}^{a c o u s t i c}$ and $q_{b}^{D E P M}$ for the best model FE-g. Differences occurred only after the 12th decimal value. Hence there is no optimal value for the constant of proportionality and assuming $q_{b}^{\text {acoustic }}=1$ seems as good a choice as any other value.

\subsection{Comparison of biomass estimates with model outputs using catch data}

The ICES working group in 2005 produced stock estimates on January 1 for the years 1987-2005 (see ICES, 2005) using the stock assessment package ICA (Patterson and Melvin, 1996). ICA uses survey indices and commercial catch data for the estimation. In order to obtain total biomass estimates in mid May at the time of the biomass estimates calculated in this paper, ICA numbers were projected forward using the formula (ICES 2005, p 418)

$$
\hat{B}_{a, t}^{\text {may }}=w_{a, t} \hat{N}_{a, t}^{j a n} \exp \left(-\frac{4.5}{12} \hat{F}_{t} S_{a}-\frac{4.5}{12} M\right) \text { a }=1, \ldots, 5
$$

where $\hat{N}_{a, t}^{j a n}$ is the estimated stock number for age $a$ in year $t, w_{a, t}$ is mean weight at age in the stock, $\hat{F}_{t}$ is the estimated annual fishing mortality which is applied pro rata, $S_{a}$ is fisheries selectivity (fixed to $0.45,1,0.99,0.79$ and 0.79 for ages 1 to 5 respectively). Note that in ICA animals become one year older in January although anchovy spawn in spring (April - June) in the Bay of Biscay. Natural mortality $\mathrm{M}$ is assumed constant for all ages and years. All parameter estimates were taken from the 
2005 assessment. As the fishing mortality for 2005 was unknown, the values for 2004 were applied, similarly for the mean weight at age.

ICA biomass estimates lay within the $95 \%$ confidence intervals of estimates obtained with model FE-g although generally at the lower end (Figure 8). Note that ICA estimates were based on the assumption of $q_{b}^{D E P M}=1$ whereas for model estimates obtained here $q_{b}^{\text {acoustic }}=1$ and $q_{b}^{D E P M}=0.73 q_{b}^{\text {acoustic }}$ (see Table 4) which explains the difference.

\section{Discussion}

A simple model for fish stock assessment using two biomass survey indices and no catches was presented and its properties explored using simulations. These simulation studies showed that one parameter, the standard deviation of biomass growth $\sigma_{\mathrm{g}}$, is only estimable if the true value is at least 0.2. Furthermore, in both the simulation studies and the anchovy case study, estimates of several parameters were found to be strongly correlated among each other, for example estimates of $\sigma_{\mathrm{g}}$ with those of mean recruitment $\mu_{R}$, the constant of proportionality $q_{R}$ and the observation error $C V_{1}$. Due to setting the constant of proportionality for the total biomass index $q_{b}=1$, all total biomass estimates are proportional to this survey index. In terms of using these stock estimates for management this means that only relative trends are available.

The test using the NRC simulated data (NRC, 1998) showed that model performance was satisfactory compared to a number standard stock assessment methods tested in that study. The estimated depletion was within $25 \%$ of the true value for four out of six simulation sets. For set 3 , the change in catchability in the middle of the time series threw the model off track. Similarly, none of the six assessment model variants using only survey data that were tested by the NRC was able to provide reasonable estimates for this data set (Table 3 , last column). For simulation set 5 , two out of five methods achieved depletion estimations within the $25 \%$ error bound, while in this study the relative error was slightly larger (33\%). Comparing root mean squared errors for normalised time series for total biomass and recruits showed that the proposed model achieved a lower RMSE value for total biomass estimates, errors being typically about half those for recruits. In summary, the proposed model performed better than a number of those tested by the NRC, although the assumed population dynamics are rather simple.

The application to Bay of Biscay anchovy illustrated the advantage of using a model compared to using the survey indices directly for stock assessment as it allowed reconciliation of two independent survey index series obtained using quite different sampling methods. All three models performed satisfactorily for total biomass estimates, though the 95\% confidence bands were wide. A large increase in precision was achieved when observations errors were fixed instead of being estimated (model FE-g-CV). However, as shown by the residual plots, the recruitment model could be improved for anchovy, perhaps by including additional information or a stock-recruitment relationship. Various studies have been carried out to develop predictive models of anchovy recruitment using environmental variables (e.g. Borja et al. 1998). Nevertheless, as De Oliveira et al. (2005) have concluded from simulations, improved predictions can only be expected if indeed there is a strong link between environmental conditions and subsequent recruitment.

Carrying out parameter estimation in a maximum likelihood framework allowed to compare different models for anchovy using likelihood ratio tests and to conclude that interannual variations in biomass growth were not estimable. Hence the best model was one with constant biomass growth, a feature which it has in common with the model proposed by Hoenig and Gedamke (2007), though in their case it was constant survival, because their model refers to abundance instead of biomass. In contrast to these authors, a model with constant biomass was selected as a result of model selection, not assumed a priori. An essential lesson to be drawn from the simulation studies and the anchovy application is that there can be extrinsic parameter redundancy in the proposed model depending on the data used and that there is intrinsic parameter redundancy for certain parameter values, in particular for small values for the variance of biomass growth. It is therefore important when applying the model to check for extrinsic parameter redundancy by analysing the Hessian matrix of the fitted model and to consider a range of models in order to select the most suitable model for the case at hand.

In terms of using model stock estimates for management, different ideas for using relative stock estimates have been put forward in the literature. Estimates could be scaled to absolute stock size using catch based stock assessment results, e.g. VPA estimates for years were the model has converged (Korsbrekke et al., 2001) or be made relative to some measure of virgin stock size (Porch 
et al., 2006). Harvest control rules using changes in stock size to determine required changes in quotas or fishing effort are another possibility.

When considering using the biomass estimates for the management of anchovy, one has to bear in mind that the management of small pelagics is generally impaired by the unpredictability of recruitment, as the incoming year class will contribute the bulk of the current year's catches (Hampton, 1996). Indeed, the estimated standard deviation for the lognormal distribution of anchovy recruitment in the Bay of Biscay was 0.9 which is rather high compared to values generally below 0.6 found for a range of species, including herring and anchovy in other areas (see summary table 2 in Beddington and Cooke, 1983), or New Zealand snapper (Maunder and Deriso, 2003). In this situation, the only option might be to closely follow the stock using scientific survey data and opt for a flexible and reactive management strategy (Fréon et al., 2005; Uriarte et al., 1996). The proposed model could then provide smoothed stock biomass estimates which could feed into a harvest control rule.

\section{Acknowledgment}

This work was partially funded by the European Commission under project Fisboat (number 502572). Benoît Mesnil provided the simulated data for simulation study 2 and made useful comments on an earlier version of this manuscript. Two anonymous referees and Doug Butterworth are gratefully acknowledged for insightful comments and suggestions.

\section{References}

Beare, D.J., Needle, C.L., Burns, F., Reid, D.G., 2005. Using survey data independently from commercial data in stock assessment: an example using haddock in ICES Division VIa. ICES Journal of Marine Science 62, 996-1005.

Beddington, J.R., Cooke, J.G., 1983. The potential yield of fish stocks. pp. 1-47.

Bergh, M.O., Butterworth, D.S., 1987. Towards rational harvesting of the South African anchovy considering survey imprecision and recruitment variability. South African Journal of Marine Sciences 5, 937-951.

Borja, A., Uriarte, A., Egaña, J., Motos, L., Valencia, V., 1998. Relationship between anchovy (Engraulis encrasicolus L.) recruitment and environment in the Bay of Biscay (1967-1996). Fisheries Oceanography 7, 375-380.

Collie, J.S., Sissenwine, M.P., 1983. Estimating population size from relative abundance data measured with error. Canadian Journal of Fisheries and Aquatic Sciences 40, 1871-1879.

Cook, R.M., 1997. Stock trends in six North Sea stocks as revealed by an analysis of research vessel surveys. ICES Journal of Marine Science 54, 924-933.

De Oliveira, J.A.A., Uriarte, A., Roel, B.A., 2005. Potential improvements in the management of Bay of Biscay anchovy by incorporating environmental indices as recruitment predictors Fisheries Research 75, 2-14.

Fréon, P., Cury, P., Shannon, L., Roy, C., 2005. Sustainable exploitation of small pelagic fish stocks challenged by environmental and ecosystem changes: a review. Bulletin of Marine Science 76, 385462.

Gimenez, O., Viallefont, A., Catchpole, E.A., Choquet, R., Morgan, B.J.T., 2004. Methods for investigating parameter redundancy. Animal Biodiversity and Conservation 27.1, 1-12.

Hampton, I., 1996. Acoustic and egg-production estimates of South African anchovy biomass over a decade: comparisons, accuracy, and utility ICES Journal of Marine Science 53, 493-500.

Hilborn, R., Walters, C.J., 1992. Quantitative fisheries stock assessment: Choice, dynamics and uncertainty. Chapman and Hall, New York, p. 570.

Hoenig, J.M., Gedamke, T., 2007. A simple method for estimating survival rate from catch rates from multiple years. Transactions of the American Fisheries Society 136, 1245-1251.

ICES, 2005. Working Group on the Assessment of Mackerel, Horse Mackerel, Sardine and Anchovy. p. 631.

ICES, 2006. Report of the Working Group on the Assessment of Mackerel, Horse Mackerel, Sardine and Anchovy. p. 592.

Korsbrekke, K., Mehl, S., Nakken, O., Pennington, M., 2001. A survey-based assessment of the Northeast Arctic cod stock. ICES Journal of Marine Science 58, 763-769.

Massé, J., 1996. Acoustic observations in the Bay of Biscay: Schooling, vertical distribution, species assemblages and behaviour. Scientia Marina 60 (Suppl 2), 227-234. 
Maunder, M.N., Deriso, R.B., 2003. Estimation of recruitment in catch-at-age models. Canadian Journal of Fisheries and Aquatic Sciences 60, 1204-1216.

Mesnil, B., 2003. The catch-survey analysis (CSA) method of fish stock assessment: an evaluation using simulated data. Fisheries Research 63, 193-212.

NRC, 1998. Improving Fish Stock Assessments. National Academy Press, Washington, DC, p. 177.

Patterson, K.R., Melvin, G.D., 1996. Integrated Catch at Age Analysis version 1.2. SOAEFD, Aberdeen, p. 60.

Petitgas, P., Massé, J., Beillois, P., Lebarbier, E., Le Cann, A., 2003. Sampling variance of species identification in fisheries-acoustic surveys based on automated procedures associating acoustic images and trawl hauls. ICES Journal of Marine Science 60, 437-445.

Porch, C.E., Eklund, A.-M., Scott, G.P., 2006. A catch-free stock assessment model with application to goliath grouper (Epinephelus itajara) off southern Florida. Fishery Bulletin 104, 89-101.

Skaug, H.J., Fournier, D.A., 2006. Automatic approximation of the marginal likelihood in non-Gaussian hierarchical models. Computational Statistics and Data Analysis 51, 699-709.

Somarakis, S., Palomera, I., Garcia, A., Quintanilla, L., Koutsikopoulos, C., Uriarte, A., Motos, L., 2004. Daily egg production of anchovy in European waters. ICES Journal of Marine Science 61, 944958.

Uriarte, A., Prouzet, P., Villamor, B., 1996. Bay of Biscay and Ibero Atlantic anchovy populations and their fisheries. Scientia Marina 60 (Suppl. 2), 237-255.

Wood, S.N., 2006. Generalized additive models. An introduction with R. Chapman \& Hall/CRC, Boca Raton, p. 391.

\section{Tables}

Table 1. Model parameter definitions and values used for simulation study 1.

\begin{tabular}{|c|c|c|c|}
\hline Parameter & Description & Eq. & $\begin{array}{l}\text { Value for } \\
\text { simulation study } \\
1\end{array}$ \\
\hline$\mu_{\mathrm{R}}$ & mean recruitment (base Normal distribution) & (2) & 10 \\
\hline$\sigma_{\mathrm{R}}$ & standard error of recruitment (base Normal distribution) & (2) & 0.5 \\
\hline$g_{1}$ & biomass growth in year 1 & (3) & $\exp (-1)$ \\
\hline$\sigma_{g}$ & standard error of biomass growth & (3) & $\begin{array}{l}0.02 \text { (small) } \\
0.2 \text { (large) }\end{array}$ \\
\hline$q_{b}{ }^{k}$ & $\begin{array}{l}\text { constant of proportionality for total biomass index for } \\
\text { survey k }\end{array}$ & (4) & 1 (fixed) \\
\hline$q_{r}{ }^{k}$ & $\begin{array}{l}\text { constant of proportionality for recruit biomass index for } \\
\text { survey } k\end{array}$ & (5) & 0.3 \\
\hline$C V_{1}^{k}$ & $\begin{array}{l}\text { coefficient of variation of biomass indices on original } \\
\text { scale for survey } k\end{array}$ & (4) \& (5) & 0.15 \\
\hline $\mathrm{B}_{1}$ & Total biomass year 1 & (1) & 80000 \\
\hline
\end{tabular}


Table 2. Correlations (minimum:median:maximum) between parameter estimates in simulation study 1 for scenario with $\sigma_{g}=0.2$ and use of recruit and total biomass indices.

\begin{tabular}{llllll}
\hline & $\mu_{R}$ & $\sigma_{R}$ & $g_{1}$ & $\sigma_{g}$ & \\
\hline$\sigma_{R}$ & $-0.28: 0.1: 0.37$ & & & \\
$g_{1}$ & $-0.95:-0.5: 0.22$ & $-0.03: 0.08: 0.29$ & & \\
$\sigma_{g}$ & $-0.17: 0.21: 0.86$ & $-0.42:-0.01: 0.19$ & $-0.78: 0: 0.58$ & & \\
$q_{r}$ & $-0.97:-0.74:-0.25$ & $-0.03: 0.13: 0.41$ & $-0.29: 0.67: 0.99$ & $-0.92:-0.29: 0.19$ & $-0.55:-0.01: 0.48$ \\
$C V_{1}$ & $-0.42: 0.01: 0.45$ & $-0.26-0.070 .02$ & $-0.47-0.010 .62$ & $-0.78:-0.2: 0.31$ & $-0.44:-0.08: 0.38$ \\
$B_{1}$ & $-0.28: 0.06: 0.42$ & $-0.07:-0.01: 0.05$ & $-0.7:-0.36: 0.14$ & $-0.54: 0: 0.4$ & $-0.31: 0.04: 0.37$ \\
\hline
\end{tabular}

Table 3. Specifications of simulated data (expanded from NRC 1998) and performance results for biomass random effects model. In bold proportion of models in NRC test using only survey information passing $\pm 25 \%$ criterion. RMSE root mean square error.

\begin{tabular}{|c|c|c|c|c|c|c|c|c|}
\hline Set & $\begin{array}{l}\text { Population } \\
\text { trend }\end{array}$ & Survey q & $\begin{array}{l}\text { Survey } \\
\mathrm{cv}\end{array}$ & $\begin{array}{l}\text { Recruit } \\
\text { biomass } \\
\text { RMSE }\end{array}$ & $\begin{array}{l}\text { Total } \\
\text { biomass } \\
\text { RMSE }\end{array}$ & $\begin{array}{l}\text { Depletion } \\
\text { estimate }\end{array}$ & $\begin{array}{l}\% \text { error in } \\
\text { depletion } \\
\text { estimate }\end{array}$ & $\begin{array}{l}\text { Prop. } \\
\text { models in } \\
\text { NRC test }\end{array}$ \\
\hline 1 & Depletion & Constant & 0.3 & 0.56 & 0.22 & 0.07 & -23.7 & $1 / 5$ \\
\hline 2 & Depletion & Constant & 0.3 & 0.44 & 0.21 & 0.08 & -6.0 & $3 / 5$ \\
\hline 3 & Depletion & $\begin{array}{l}\text { Higher } \\
\text { later }\end{array}$ & 0.3 & 0.78 & 0.80 & 0.47 & 187.0 & $0 / 6$ \\
\hline 4 & Depletion & Constant & 0.3 & 0.54 & 0.18 & 0.06 & 13.4 & $2 / 5$ \\
\hline 5 & Recovery & Constant & 0.3 & 0.55 & 0.20 & 4.7 & 33.4 & $2 / 5$ \\
\hline 6 & 2-way trip & Constant & 0 & 0.001 & 0.05 & 0.33 & -6.4 & not used \\
\hline
\end{tabular}


Table 4. Model description and parameter estimates with coefficients of variation in brackets for anchovy case study. Results for models with $q_{b}^{a c o u s t i c}=1 . p-$ values for likelihood ratio test with model in line above.

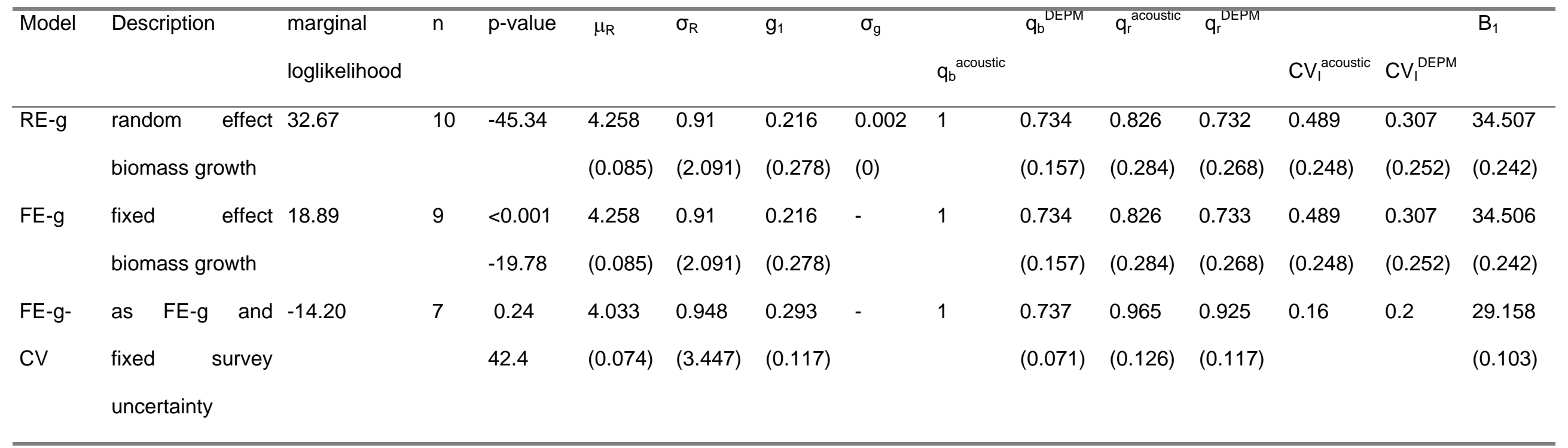


Table 5. Correlation coefficients for parameter estimates of model FE-g fitted to anchovy case study. See Table 1 for parameter definitions. acoustic: acoustic survey indices; DEPM: daily egg production method survey indices.

\begin{tabular}{|c|c|c|c|c|c|c|c|c|}
\hline & $\mu_{\mathrm{R}}$ & & $g_{1}$ & $\mathrm{q}_{\mathrm{b}}^{\text {DEPM }}$ & $\mathrm{q}_{\mathrm{r}}^{\text {acoustic }}$ & $\mathrm{q}_{\mathrm{r}}^{\text {DEPM }}$ & $\mathrm{CV}_{\mathrm{I}}^{\text {acoustic }}$ & $C V_{1}^{D E P M}$ \\
\hline$\overline{\sigma_{R}}$ & 0.36 & & & & & & & \\
\hline g & -0.49 & 0.13 & & & & & & \\
\hline $\mathrm{q}_{\mathrm{b}}{ }^{\text {DEPM }}$ & -0.38 & -0.01 & 0.08 & & & & & \\
\hline $\mathrm{q}_{r}^{\text {acoustic }}$ & -0.46 & 0.14 & 0.63 & 0.44 & & & & \\
\hline $\mathrm{q}_{\mathrm{r}}^{\text {DEPM }}$ & -0.58 & 0.11 & 0.76 & 0.50 & 0.73 & & & \\
\hline$C V_{1}^{\text {acoustic }}$ & 0.33 & 0.00 & -0.39 & -0.04 & -0.20 & -0.47 & & \\
\hline $\mathrm{CV}_{\mathrm{I}}^{\mathrm{DEPM}}$ & -0.29 & -0.02 & 0.43 & 0.06 & 0.21 & 0.44 & -0.44 & \\
\hline $\mathrm{B}_{1}$ & 0.26 & 0.00 & -0.18 & -0.39 & -0.24 & -0.36 & 0.34 & -0.26 \\
\hline
\end{tabular}



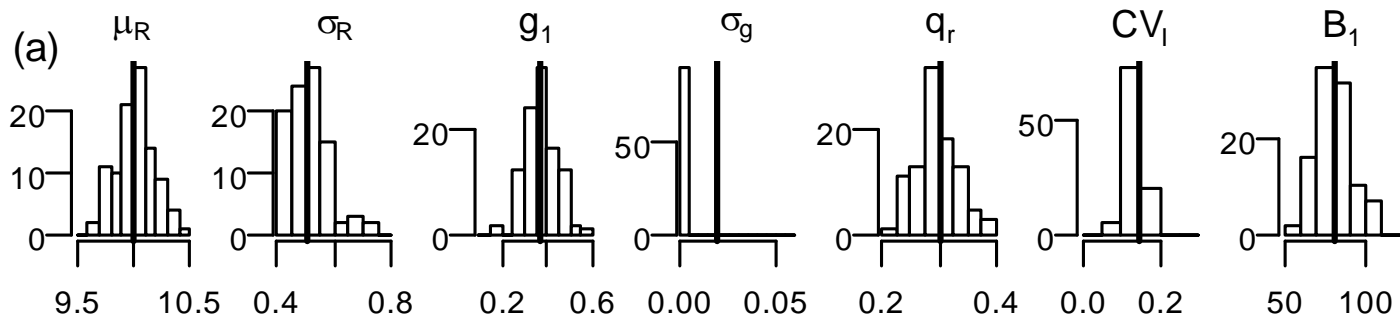

(b)
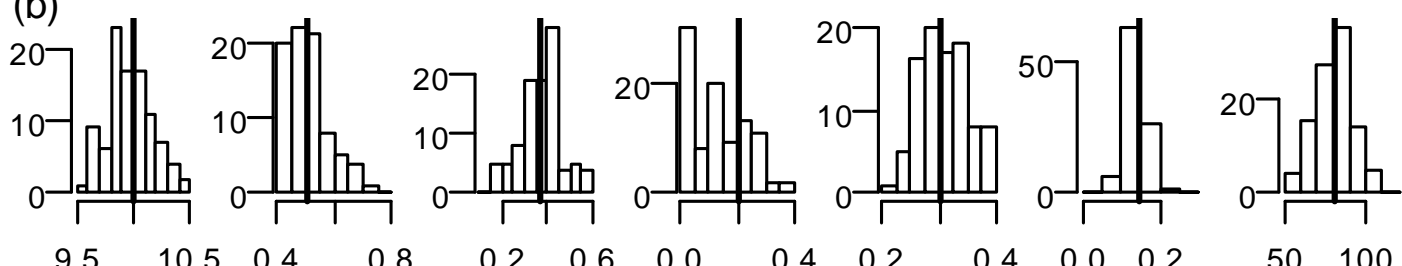

$\begin{array}{llll}9.5 & 10.5 & 0.4 & 0.8\end{array}$

$0.2 \quad 0.6 \quad 0.0$

$0.4 \quad 0.2$

$\begin{array}{lll}0.4 & 0.0 & 0.2\end{array}$

50100
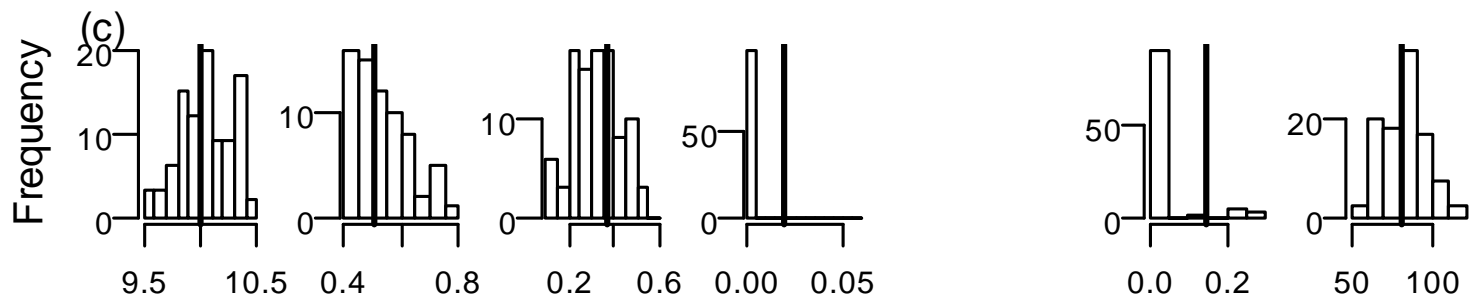

(d)
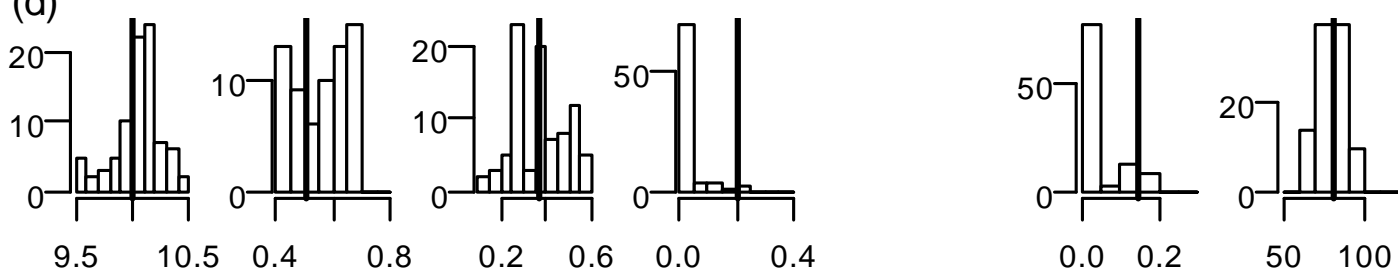

(e)
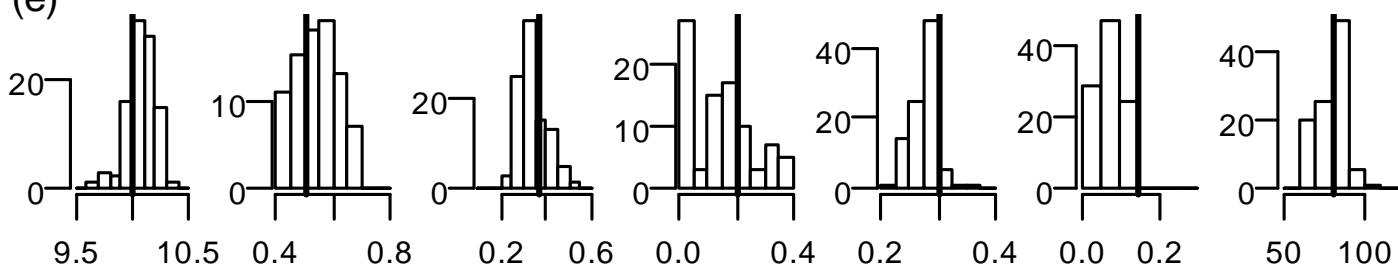

Parameter value

Figure 1: Estimates and true values (vertical lines) from simulation study 1 (see table 1 for parameter values). a) Use of total and independent recruit biomass index for scenario with $\sigma_{g}=0.02 \mathrm{~b}$ ) Use of total and recruit biomass index for scenario with $\sigma_{g}=0.2 ; \mathrm{c}$ ) Use of only total biomass survey index for estimation for scenario with small $\sigma_{g}$ d) Use of only total biomass survey index for estimation for scenario with large $\sigma_{g}$; e) Use of total and recruit biomass with correlated errors for scenario with large $\sigma_{\mathrm{g}}$. 


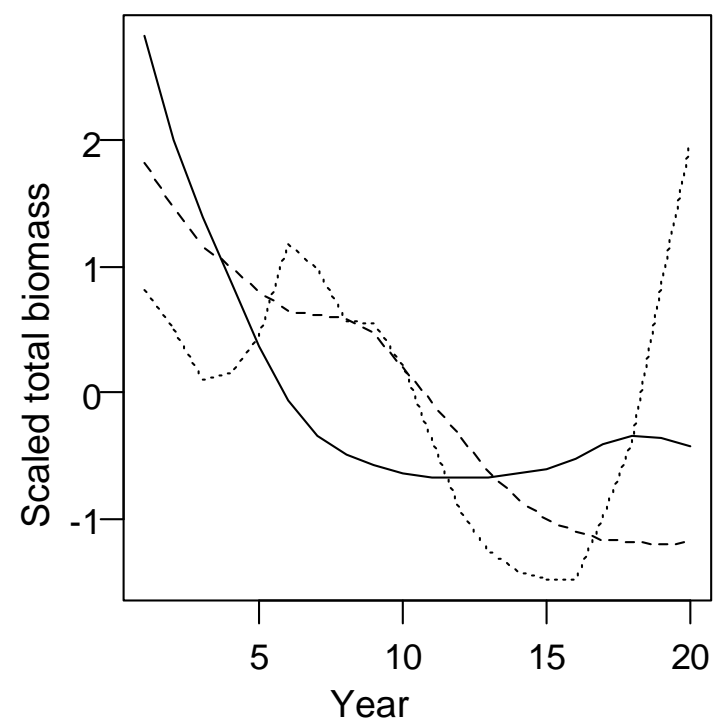

Figure 2. Simulated population biomass trajectories for simulations study 2: scenario F1 (continuous line), scenario F2 (dashed line) and scenario M2 (dotted line).
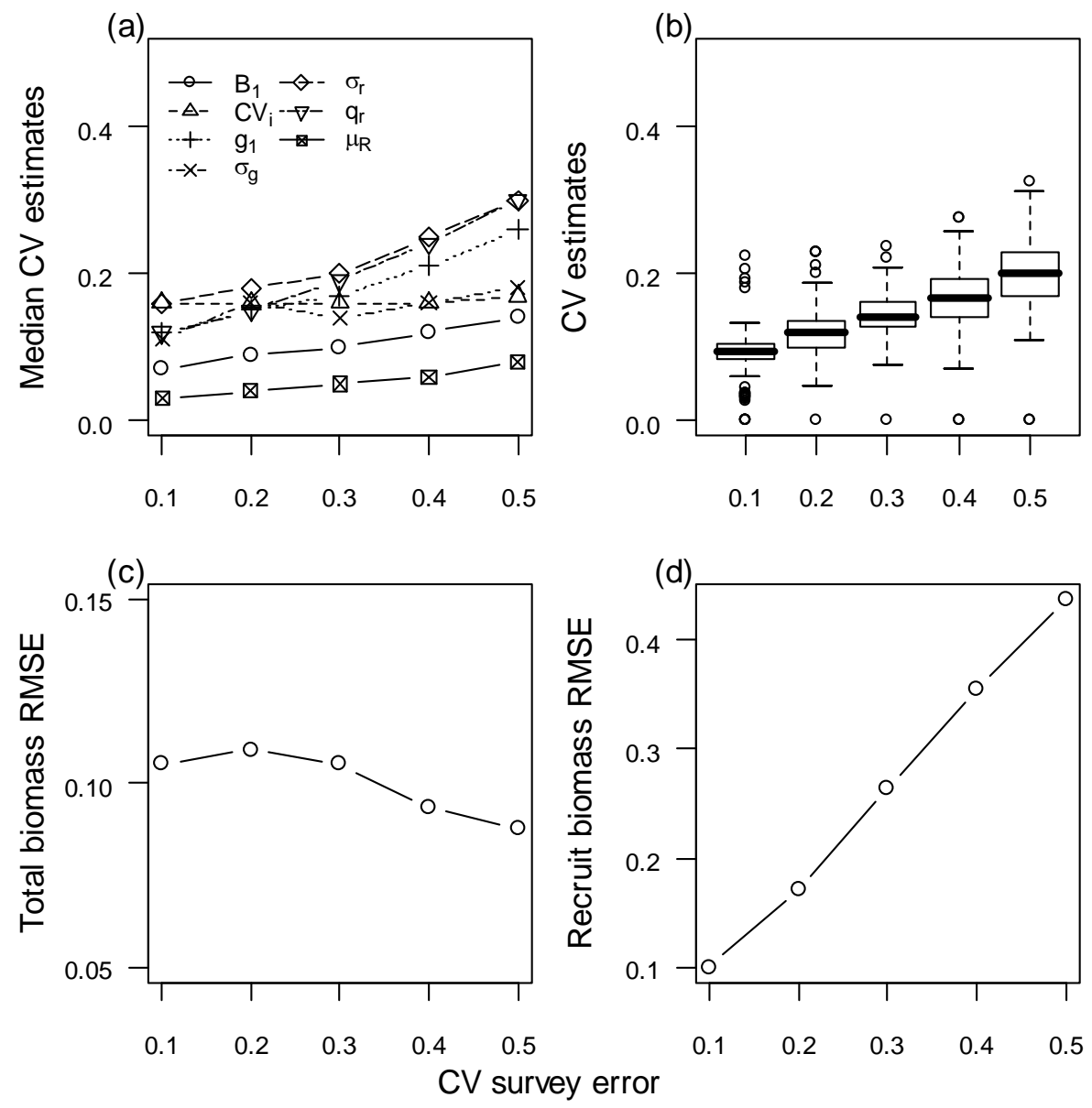

Figure 3. Impact of survey uncertainty $\left(C_{1}\right)$ on coefficients of variations of parameter estimates for scenario F1 of simulation study 2. RMSE is the residual mean squared error. 


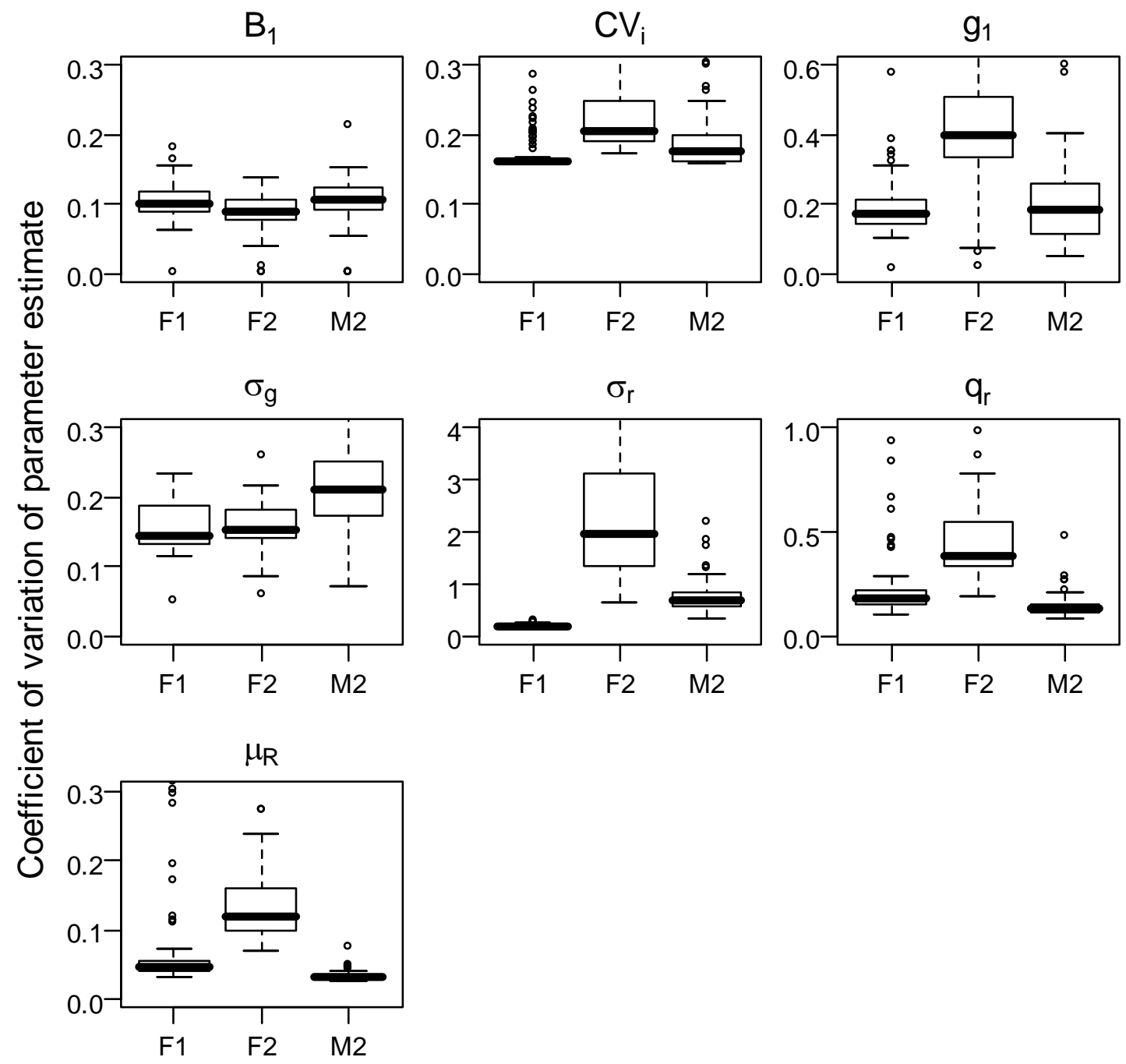

\section{Scenario}

Figure 4. Coefficient of variations of model parameter estimates for different fishing scenarios. F1 constant fishing mortality; F2 higher fishing mortality at the end of the series; M1 as F1 but higher natural mortality, see figure 2 for simulated population trajectories. 

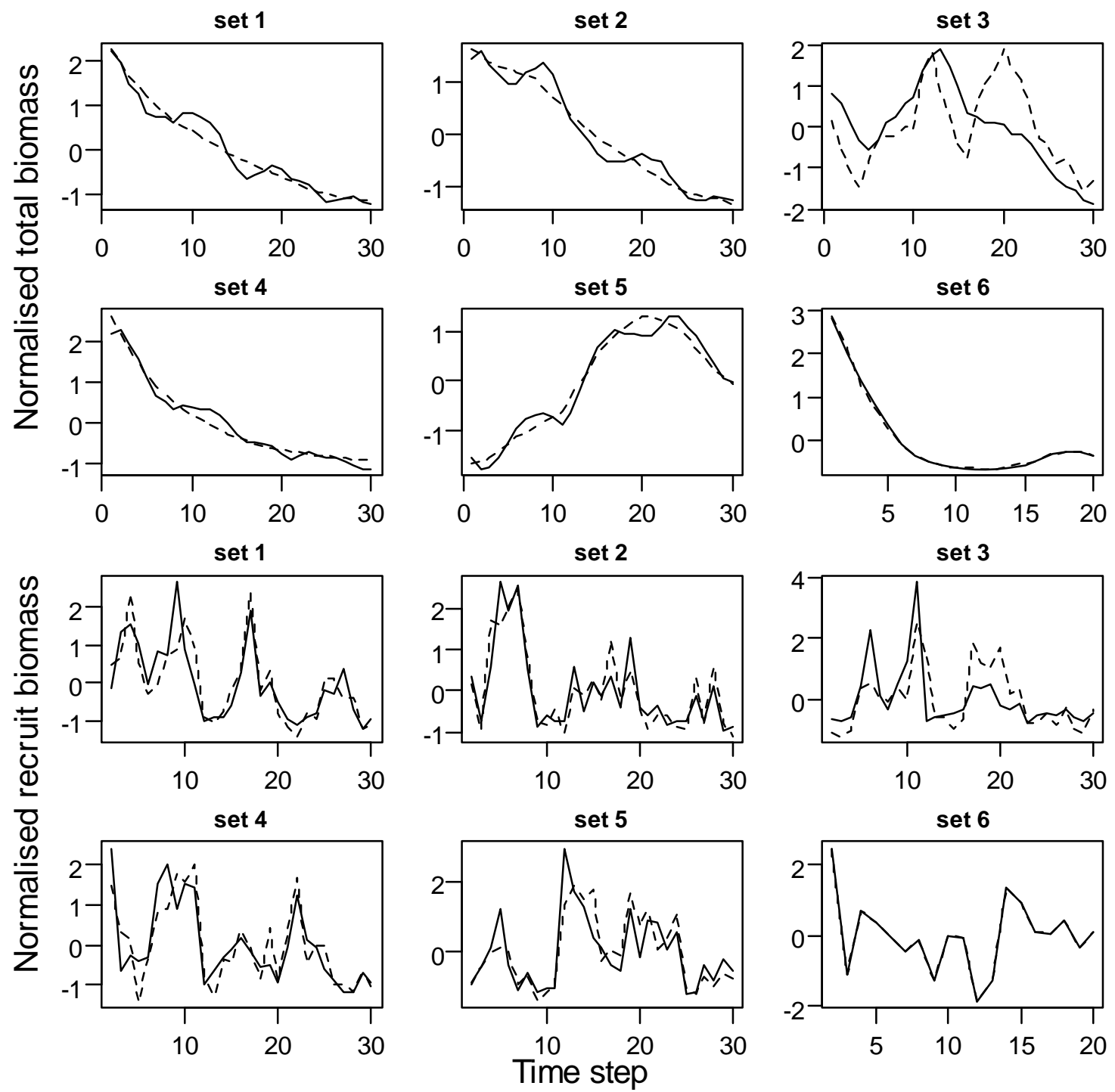

Figure 5: Results for simulation study 3. True (continuous line) and model estimates (dashed line) for normalised total and recruit biomass.

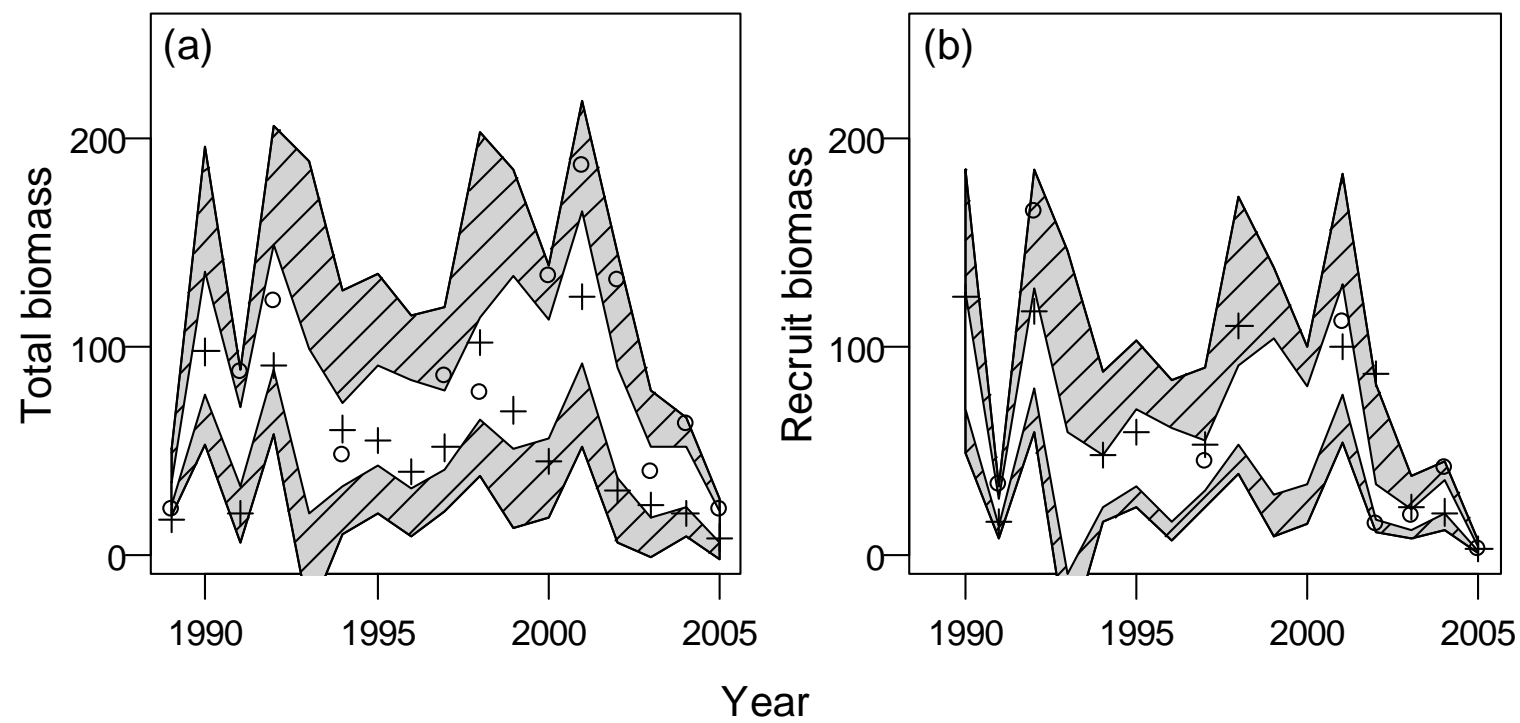


Figure 6. Confidence bands (95\%) derived from the fitted Hessian matrix for biomass estimates for recruits (age 1) and total population biomass for anchovy case study for model RE-g with random effect biomass growth (grey), model FE-g with fixed effect biomass growth (shaded) and model FE-gCV with fixed effect biomass growth and fixed survey CV (white). Acoustic $\left(^{\circ}\right)$ and DEPM $(+)$ survey indices were transformed into population biomass indices by multiplying them with the inverse of the estimated survey coefficients of proportionality for model FE-g.

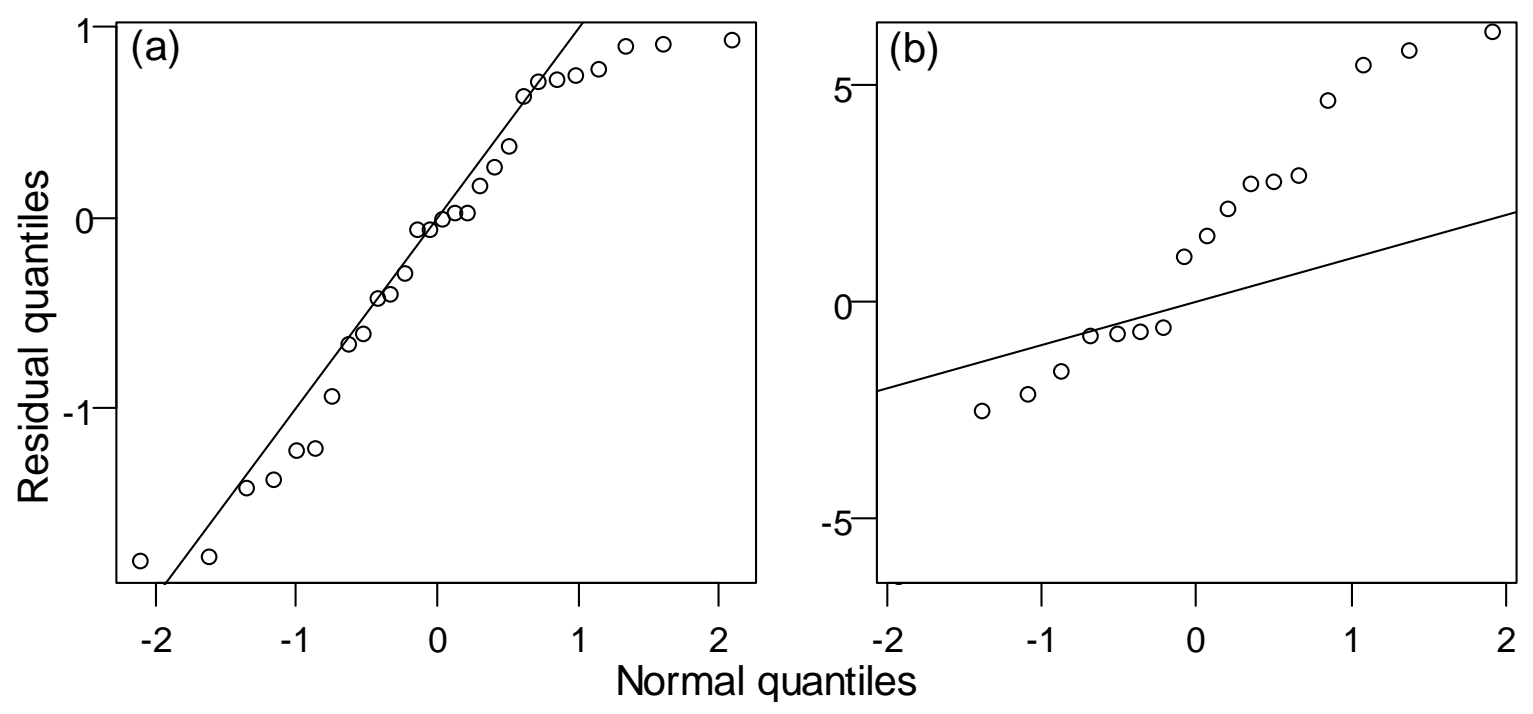

Figure 7. QQ-plots for residuals for total biomass and recruitment biomass estimates for model FE-g for anchovy case study. a) total biomass, b) recruit biomass.

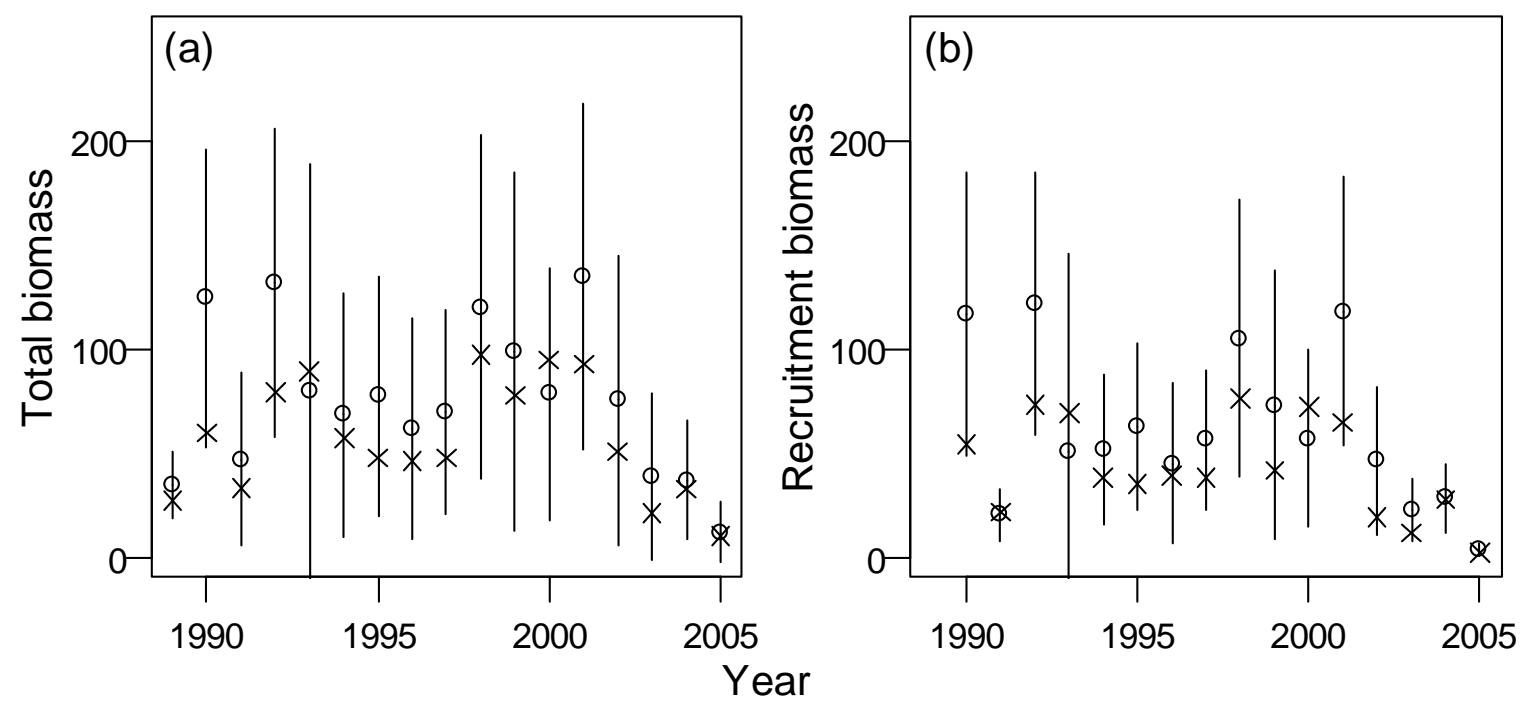

Figure 8. Comparison of a) total and b) recruitment biomass estimates for model FE-g $\left({ }^{\circ}\right)$ with estimates derived from the 2005 ICES stock assessment $(x)$ using the same survey indices and additionally commercial catches. 